\title{
Factors that Influence Academic Teacher's Acceptance of E-Learning Technology in Blended Learning Environment
}

\author{
Snježana Babić \\ Polytechnic of Rijeka, Business Department, Rijeka, \\ Croatia
}

\section{Introduction}

The idea of distance learning as the concept of learning at one's own pace independent of time and place, originated in 19th century. The Open University of United Kingdom, which introduced blended learning in 1969, had the crucial role in introducing the distance learning into the higher education. The term e-learning (electronically supported learning) was introduced in 1995, and its most common definition is: learning and teaching using information and communications technology, or more broadly, e-learning technology.

Blended model of learning combines different models of learning and teaching: in traditional classroom (which provides e-learning technologies) and virtual learning environment. Virtual Learning Environment (VLE) is a component or subsystem of the Managed Learning Environment (MLE), where students and teachers take part in different types of online interaction, and whose focus is on managing and facilitating the learning process while providing the required resources. The commonly used synonym for VLE is Learning Management System (LMS). MLE includes various information systems and processes of the higher education, and together with VLE they make a part of virtual campus (The Joint Information System Committee [JISC], 2011).

One of the definitions of virtual campus is: "...refers to a specific format of distance education and on-line learning in which students, teaching staff and even university administrative and technical staff mainly 'meet' or communicate through technical links" (benchmarking of Virtual Campuses [BENVIC], 2011).

Higher education teacher can find the service of using VLE at certain institutions, which can use the service developed within the institution or at the university level. In practice, most commonly used are commercial software packages (integrated set of tools for communication, knowledge evaluation, collaboration, monitoring and other) such as WebCT and Blackboard, and among Open Source packages, Moodle and Claroline.

Introducing e-learning into higher education institution brings about changes on organizational, economical and technical level, however, the practice shows that e-learning has been introduced into such institutions in various ways which resulted in different quantity and quality of the education processes using e-learning technology. To improve the effectiveness of e-learning, the need occurred for developing the quality management system in the field of e-learning (Kermek et al., 2007). Those standards are: ISO/IEC 19796- 
1:2005 (Information Technology - Learning, Education and Training - Quality Management, Assurance and Metrics - Part 1: General Approach, 2005) which provides a framework for quality management and consists of reference model describing the education processes and subprocesses in e-education, and ISO/IEC 19796-3:2009 (Information Technology Learning, Education and Training - Quality Management, Assurance and Metrics - Part 3: Reference methods and metrics, 2009) which extends the previous reference framework by providing methods and metrics required to implement quality management and quality assurance systems for stakeholders designing, developing or utilizing e-learning technology. Processes related to e-education are compared to the software development process, where the basis for quality standards is taken from the domain of software engineering (Kermek et al., 2007). Based on this, Marchall \& Mitchell (2004) defined E-learning maturity model for estimating the organization's level of maturity relating to the e-education processes and their improvement. The improvement of education processes depends on the development of capabilities in all their elements, from the institution in charge to the every single individual involved in the educational system, and in this case it is important to emphasize teacher competences.

On the other hand, the quality and usability of the virtual learning environment are the key influencers on the learning outcome, i.e., student satisfaction. The usability of the e-learning technologies, as the main element of the e-learning success, includes pedagogical and technical usability. Pedagogical usability refers to the support in the process of teaching and learning, while technical usability refers to the interaction between the user and the computer (Melis et al., 2003). Due to the mentioned facts, to create a virtual learning environment, apart form the teacher as an expert in a certain field of study, a team of experts is required: multimedia experts, programmers, administrators, instructional designers and similar experts. However, the practice shows that often teachers are the ones who perform many different roles themselves.

With regards to the complexity of the proper use of e-learning in teaching, the results of the research indicate the slow manner of teachers accepting e-learning. For that reason, a question is being asked: Which factors influence the higher education teacher's acceptance of elearning?

Numerous authors have researched many factors from different aspects, they have monitored introducing e-learning as an innovation diffusion in organization, introducing and accepting new information system, communication between human and the machine, psychology, pedagogy, reengineering the education/business process and other. During the research they have used existing theories and models of technology and innovation acceptance.

Keller (2009) approaches the teacher's acceptance of VLE as an innovation diffusion from the aspect of organizational learning, while Nanayakkara and Whiddett (2005) group factors as individual, organizational and system factors. Argawal (2000) defines the following categories of factors related to the personal acceptance of the information technology in organizations: personal differences, situational factors, social influence, organizational factors, beliefs and attitudes. Osika and Buteau (2009) monitor acceptance of the e-learning technology through motivational factors, which they group as intrinsic factors (beliefs, sense of competence, anxiety) and extrinsic factors (institutional factors).

In professional development individual's commitment to the quality of his or her work is shown through the change in attitudes and values, development of skills and competences, 
and using certain tools and instruments which results in quality work (Ehlers, 2007). Baia (2009) confirmed the influence of the factor commitment to pedagogical quality on technology acceptance, which is influenced by: belief about learning technologies, academic title and years of work experience.

Competence perception and confirmation of the initial expectation (attitude) influence the teacher's satisfaction through perception of usefulness, where the attitude related to the teacher's education (Ø. Sørebø \& A. M. Sørebø, 2008) is the confirmation of the initial expectation.

The following pages contain the overview of the most commonly used theories and models of accepting technology and innovation, as well as key responsibilities of teachers in blended learning process for better understanding of the concept of higher education teacher competence in the field of e-learning. Furthermore, categories of factors have been singled out in which there is an overview of those factors which, as found in recent studies, showed connection with teacher's accepting e-learning technology. The conclusion contains the categories with key factors which can aid future researchers in defining theoretic models as the foundation for future empirical researches.

\section{Education process in blended learning environment and the teacher competence concept}

To describe a teaching scenario in any form of e-learning and in different educational environments, a reference model ISO/IEC 19796-1 can be used, which includes the complete life-long learning cycle. The model is a framework consisting of two parts: generic process model and generic descriptive model. Generic process model is divided into 7 basic processes and 38 subprocesses, and the following is the description of the basic processes (Pawlowski, 2006):

Needs Analysis: identification and description of requirements, demands, and constraints of an educational project

Framework Analysis: identification of the framework and the context of an educational process

Conception /Design: conception and design of an educational process

Development/Production: realization of concepts

Implementation: description of the implementation of technological components

Learning Process: realization and use of the learning process

Evaluation/Optimization: description of the evaluation methods, principles, and procedures There are numerous instructional design models (systematic approach to analysis, design, development, implementation and evaluation of the study material for learning according to the set learning outcomes, following the analysis of student needs) which teachers can use to design different education processes in blended form. Some of the instructional design models are: Dick and Carey, rapid prototyping, Knirk and Gustafson and others, among which the most commonly used in higher education is ADDIE (Analyze, Design, Develop, Implement, Evaluate) model.

Academic teachers most frequently use their own non-standardised models, and very often use the virtual learning environment only for access to study material. In practice, the search for the best blended learning model in a particular context boils down to combining the advantages and disadvantages of traditional teaching activities and technology-mediated activities (Fig. 1) (Rothery et al., 2008). 


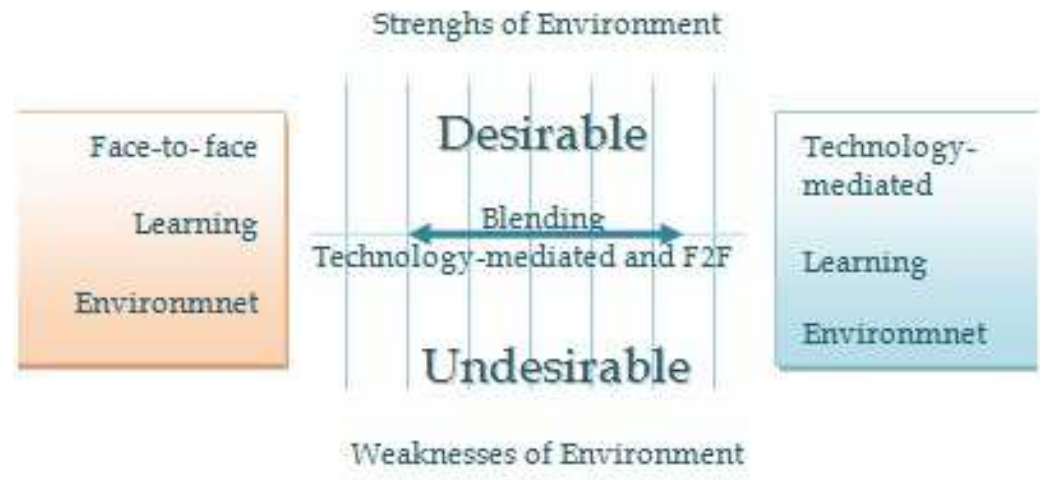

Fig. 1. Searching for the best blended learning model (Rothery et al., 2008).

The quality of the education process is one of the factors responsible for students achieving success. Creating the blended learning environment is not easy and it requires teachers to redefine the existing competences and develop new ones, during which is essential to understand the concept of the quality of e-education.

Numerous definitions of competence concept have been published, and according to Weinert (2001) it "...is a specialized system of abilities, proficiencies, or skills that are necessary to reach a specific goal". From this definition, it can be inferred that the concept of personal e-competence of the higher education teacher includes: teacher's ability to implement e-learning in his or her education process, as well as ability to adopt new competences for implementing e-learning in the education process.

With the aim of defining the concept of e-competence, numerous authors used the general competence concept, developed by Weinert (2001), as their basis. Its central idea is the learning process which together with practical experience develops new knowledge and skills that change values and form a certain attitude. Weinert (2001) emphasizes the importance of the experience and explains that competences can be learned and developed through practical values. The foundation for action lies in: attitude, knowledge and skills, and great importance is put on action competence which includes "available cognitive, motivational and social requirements for successful learning or performing an action".

Based on the mentioned general competence concept, Schneckenberg (2007) defined the ecompetence concept applicable to all levels, from institution, group, to every stakeholder in higher education environment. The concept assumes knowledge, skills and attitude as the basis for performance, which can be looked at from the aspect of pedagogical, technical, organizational and sociocultural dimension, and the action competence can be seen through four core competences: subject matter, methodology, social competence and personal competence. It is important to emphasize that the teacher's personal competence for elearning application cannot be defined without identifying situational variables in specific education scenarios which are determined by the following elements (Schneckenberg, 2007): pedagogical model (set of methods for optimum realization of communication between teacher, content and student), choice of e-learning technology, student competences for using ICT in learning activities and the characteristics of the education content, i.e., the course. Education scenario is performed in specific context with specific characteristics, therefore the more specific and less specific education contexts are the key elements of the 
aforementioned competence model. Assuming that a competent person will not apply and develop his or her competences unless motivated, the motivation component is of crucial importance and it can be intrinsic (teacher's personality, attitude and values) and extrinsic (situational and institutional factors).

Taking into consideration the same general competence concept in organization (Weintert, 2001) and the fact that e-learning is introduced into education to improve the education quality (dependent of the desire for quality performance of all the stakeholders in the educational system), Ehlers (2007) defined the concept of competence as "quality literacy". Thus he describes the ability of education stakeholders to improve in quality while emphasizing the importance of professionalism as the crucial component in quality development. He looks at the "quality literacy" concept through four dimensions of competence which lead to professionalism and quality development on all levels: quality knowledge, quality experience, quality innovation and quality analysis. "Quality literacy" is the competence concept which, besides knowledge and skills, includes: the responsibility of the stakeholders towards the surroundings, i.e., professionalism in the field of quality development in e-education.

\section{Theories and models of accepting technology and innovation}

With the aim of understanding the factors which influence teachers accepting the e-learning technology, different existing theories and models have been used, and this paper mentions only the ones used frequently in recent studies.

The model of accepting technology has its foundations in the theory of social psychology, developed by Fisbein and Ajzen (1975) as Theory of Reasoned Action (TRA) which points out key factors influencing the behavioral intent: attitude toward behavior and subjective norm; if users have the intention of accepting technology, they will do so, but under the strong influence of the environment.

In his Theory of Planned Behavior (TPB) model, Ajzen (1991) later added the factor of perceived behavioral control to the factors attitude toward behavior and subjective norm, which stems from the self-efficacy theory and is a condition for change in behavior.

One of the first models of accepting technology, and most commonly used in the research is Technology Acceptance Model (TAM) (Fig. 2) developed by Davis (1989), according to which the user's attitude towards technology is mainly influenced by the following factors: perceived usefulness and perceived ease of use. According to Davis (1989), perceived usefulness is defined as "the prospective user's subjective probability that using a specific application system will increase his or her job performance", while perceived ease of use is defined as "degree to which the prospective user expects the target system to be free of effort".

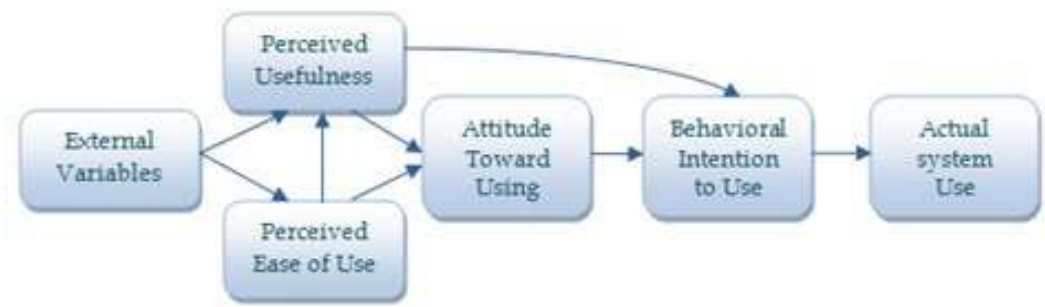

Fig. 2. Technology Acceptance Model (TAM) developed by Davis (1989). 
TAM model was later updated by its author adding numerous factors, and so have other authors; Venkatesh and Davis (2000) developed TAM2 model in which the TAM model is upgraded with the processes of cognitive influence: job relevance, output quality and result demonstrability, and the processes of social influence: subjective norm, voluntariness and image, which influence the perceived usefulness.

The next important model, very often used in the field of e-learning, was developed by Venkatesh et al. (2003) as Unified Theory of Acceptance and Use of Technology (UTAUT), according to which the following four factors influence the user's technology acceptance: performance expectancy, effort expectancy, social influence and facilitating conditions. The model emphasizes the importance of four moderators: age, gender, experience and voluntariness of use, as individual differences between users towards technology acceptance.

From the aspect of diffusing new ideas and innovations, according to Rogers (1995), four main elements have a direct influence: innovation, communication channels, time and social system. In Innovation Diffusion Theory (IDT) Rogers (1995) defined five steps through which the user goes through when deciding about accepting new technology: knowledge, persuasion, decision, implementation and confirmation. In the phase of persuasion about positive characteristics of the product/service, the user is influenced by: relative advantage, compatibility, complexity, trialability and observability. According to the decision-making about innovation acceptance, Rogers (1995) groups the users as following: innovators, early adopters, early majority, late majority and laggards (Fig. 3).

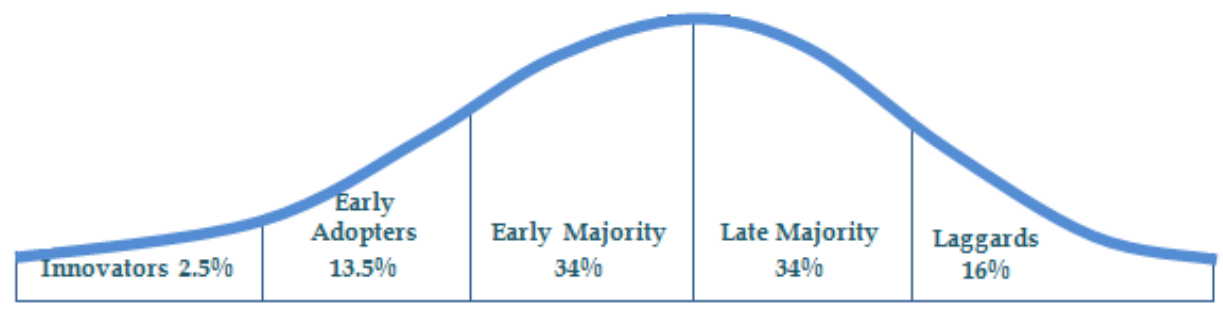

Fig. 3. Rogers Innovation Adoption Curve (Rogers, 1995).

Among early and late adopters (Fig. 3) there are systematic differences in three areas: socioeconomic, personality variables, communication behavior, and other characteristics: previous practice, wants and needs, innovativeness and social norms.

Based on Rogers' theory (1995), Moore and Benbasat (1991) developed a model for measuring user's perception of information technology's characteristics as innovation. The model was applied in the field of adopting information systems, and it consists of the following: relative advantage, compatibility, trialability, ease of use (replacement for: complexity (Rogers, 1995)), visibility and result demonstrability (replacement for: observability (Rogers,1995)), image and voluntariness.

\section{Factors that influence academic teacher's acceptance of e-learning technology}

What follows are the factors connected to the academic teacher's acceptance of e-technology, grouped in several categories. 


\subsection{Teacher competence (knowledge and skills)}

Certain knowledge and skills encourage changes in individual's values and attitudes which influence the user's behavior, as well as belief about self-efficacy.

The main prerequisite for the use of e-learning technology is: computer literacy, and the lack of computer knowledge is closely related to computer anxiety and the level of perceived usefulness of e-learning technology ( $\mathrm{Liu}, 2005)$. Computer literate person is more likely to experiment with new software. Therefore, the level of experience in working with e-learning system (LMS) is the powerful motivator in teacher's adoption of e-learning (Gautreau, 2011). It is well known that after having accepted the e-learning system, it is used on different levels. Renzi (2008) proved the existence of differences in competences between certain groups of teachers. Teachers who create virtual learning environments according to the instructional design principles transform their way of teaching. Knowledge and skills from using the instructional design model, i.e., designing the education scenario, are related to the following factors: formal education, teacher's experience and perceived technology usefulness (Renzi, 2008).

E-moderating is the key teacher competence influencing the success of the online part of the lessons, and which (according to Salmon (2000)) refers to: knowledge and skills of online moderating and online mentoring. On the organizational level of e-learning, besides the pedagogical and technical dimension of the teacher competence, Shenckenberg (2008) points out the importance of the sociocultural and organizational dimension of the competence profile when adopting e-learning. In this case, sociocultural dimension refers to the teacher's readiness to adopt new knowledge from the field of elearning, as well as communication and sharing of knowledge within certain networks, and the competence profile of academic teachers in organizational dimension includes taking part in deciding about implementation of e-learning at institutional level, working in interdisciplinary teams on solving problems due to the complexity of education using e-learning technology and managing e-learning projects which are a part of university's elearning strategy (Shenckenberg, 2008).

\subsection{Attitude and values}

In the process of accepting innovation in teaching, teacher's belief about the usefulness of the innovation plays one of the main roles and it encourages changes in the curricula (Colorado \& Eberle, 2009). Teacher's attitude and values are important motivational factor in developing and applying e-learning competence.

There have been many researches about teacher's attitude towards e-learning technology: positive (confirmation) or negative (anxiety) (Mihhailova, 2006). Less researches are oriented towards beliefs which form certain values and attitudes (Agarwal, 2000). Researches have shown that users' behavior is influenced by different beliefs or e-learning technology attributes, and according to Moore and Benbast (1991) they are: relative advantage, compatibility, trialability, ease of use, result demonstrability, observability. Most frequently confirmed attributes are: ease of use and usefulness (Gibson et al., 2008; Renzi, 2008; Keller, 2009).

Ozkan and Findik (2010) confirm the importance of the e-learning technology compatibility attribute in relation to the differences in certain academic departments, where the difference has been confirmed. Kundu et al. (2010) confirm the importance of compatibility attribute 
through the following obstacles in accepting e-learning technology: integration with other systems in organization, incompatibility in technology use and existing work practice, the problem of integrating technology and existing practice in traditional classrooms. Moscinska and Rutkowski (2011) confirm the attributes: flexibility and "user-friendly" which influence the acceptance and use of e-learning systems, and present technical characteristics of the elearning system.

It is well known that different beliefs about the value of e-learning encourage teachers to apply e-learning technology on different levels (Renzi, 2008). The perception of e-learning usefulness is formed under the influence of intrinsic and extrinsic factors, and numerous authors list: belief in institution's competitiveness, increased number of enrolled students (Osika et al., 2009), facilitated student cooperation in educational context (Lofstrom \& Nevgi, 2008), communication and additional support for students, distribution of study material, the ease of administration, the value of collaborative online work (Keller, 2009), belief in information sharing, automated activities of the learning process, value of social learning as an important part of learning in general (Renzi, 2008). Successful pedagogical use of e-learning technology depends on teacher's attitude towards technology Mihhailova, 2006). Research results show that teacher's attitude has been studied more from the technical and less from the pedagogical aspect (Mahdizadeh et al., 2008).

\subsection{Teacher's personality}

Teacher's personality is a powerful intrinsic motivational factor which influences e-learning technology acceptance. It represents a set of characteristics which make every teacher unique in education process and it is strongly influenced by the surroundings.

The most commonly studied teacher's features are: self-efficacy and anxiety, more often approached from the technical aspect. Computer anxiety is closely connected to the teacher's attitude, author suggests the possibility of understanding computer self-efficacy as a construct of perceived ease of use (Timothy, 2009). Malik et al. (2010) mention teacher's organizational commitment as an important factor in quality teaching process and Baia (2009) confirmed the influence of commitment to the pedagogical quality on the e-learning technology acceptance.

Teacher's personality is evident through teaching and learning style applied in the education process and which includes certain teaching methods and techniques, and represents a mechanism responsible for quality conveyance of the educational content influencing the student success (Grasha, 1994). Changes in the teacher's belief, attitude and values influence the teaching style. Lucas \& Wright (2009) predicts the possibility of connection between teaching style and the attitude towards the use of e-learning technology. Dugas (2006) determined a slight connection of teaching style and the degree of innovation with accepting e-learning technology.

Apart from the teacher's personality, great importance lies in the demographic and situational variables. The experience with LMS and computer experience are strong motivators in teachers' acceptance of e-learning (Gautreau, 2011). In his research Timothy (2009) did not find significant link between attitude, age and gender, which contradicts the hypothesis by Houtz and Gupta, Cully et al. (Timothy, 2009), he found a significant difference in the attitudes of the female computer users. However, Marwan and Sweeney (2010) point out to a significant connection between gender, department and academic title with the teacher's attitude towards e-learning technology. Academic title and years of work 
experience influence the commitment to the pedagogical quality which influences acceptance of e-learning technology (Baia, 2009).

\subsection{Characteristics of students and the field of study}

While creating virtual learning environment the choice of e-learning technology depends on pedagogical model, and its choice is influenced by: field of study characteristics and characteristics of the students, which both represent situational factors.

Kanuka (2006) stresses out the importance of the following factors: value and culture within certain discipline, understanding unique problems within each field of study as crucial elements when designing learning environment. Keller (2009) proved that the culture within the discipline represents the obstacle of e-learning application. Before using the virtual learning environment, reasons for the use of e-learning technology need to be defined, where, according to Rebman Jr et al. (2004), certain physical educational activities require classical approach in a traditional classroom. Knowledge is hierarchically organized and therefore it is essential to define learning outcomes within each course using knowledge taxonomy, and based on the outcomes define educational strategies and student activities (Donnelly, 2005). Numerous models of instructional design can be found in literature, however, Donnelly (2005) emphasizes that teachers mostly use non-systemized personal models because the planning of the educational structure requires: time, commitment and careful systematic approach. One characteristic of the study object (any segment of the digital study material) is: multiple use in different educational contexts; however, Parrish (2007) brings up the problem of intellectual property which limits the distribution of the study objects. Learning happens in predictable patterns that can me modeled using algorithms, which influences the development of the intelligent tutoring systems (Parrish, 2007).

Student characteristics can act as motivators for application and development of e-learning in teaching, and student capabilities (Osika et al., 2009) can be an obstacle in using elearning technology in teaching. Each student has his or her own learning style and there are various instruments that can measure those styles (Grasha, 1994). A very important student characteristic is motivation; a motivated student shows greater interest in information, the quality of information, confidence when accessing information and technology, satisfaction in work (Kumarawadu, 2011). Colorado and Eberle (2009) conclude that the level of student self-regulated learning is related to demographic data: gender, status, certify cates, completed degree of education and characteristics of the self-regulated learning: learning strategy, critical thinking, knowledge sharing, asking for help, where students who have graduated have a higher level of self-regulated learning.

On the other hand, the number of students in virtual classrooms and complexity of education scenario influence the success of virtual learning process (Salmon, 2000). Perception of student characteristics can be a part of the construct: facilitating circumstances (Ø. Sørebø \& A. M. Sørebø, 2008).

\subsection{Acquiring knowledge and skills}

The lack of knowledge about e-learning technology and the lack of skills influence the successful integration of e-learning in higher education institutions. New knowledge and skills, together with experience, encourage the change in existing value system, and finally they become attitudes influencing the teacher's behavior in the education process. On the 
other hand, the attitudes and values of other important people in a certain environment also have significant influence on developing behavior.

Formal education in the field of pedagogy influences the level of e-learning application in the education process (Renzi, 2008). Learning is a process which can be realized in different ways using current e-learning technology at various life-long learning centers, organized by different institutions. On the other hand, Samarawickrema and Stacey (2007) point out the importance of learning and support from the experienced colleagues and experts via formally organized networks, as well as informal group networks, within and outside the university, i.e., through different learning communities. Support and encouragement from the colleagues within the network are the strong motivators for the experimenting with elearning technology and teacher's eagerness and interest for introducing innovation into the education process. Keller and associates (2009) also confirm the importance of the colleague support, as well as expert help in accepting and applying e-learning, which is closely connected to the lack of time needed to invest in acquiring new pedagogical and technological competences (Keller et al., 2009). Organizational learning is strongly and reciprocally connected with individual learning. Learning is a continuous process which can be encouraged by: personal, situational and institutional motivational factors, therefore it is essential to understand their influence. Gautreau (2011) confirms the importance of teacher's personal motivation to attend the course about applying e-learning in education process, which strongly influences the successful integration of e-learning system in education process.

\subsection{Institutional factors}

Institutional factors belong to a group of extrinsic motivational factors influencing academic teacher's acceptance of e-learning technology. Numerous study results indicate that factors which influence academic teachers differ depending on the current phase of e-learning introduction into the academic institution in question. One of the key factors is the capacity and reliability of the ICT infrastructure (Nanayakkera \& Whiddett, 2005). In practice, teachers frequently list the following conditions as obstacles: access to the computer classroom, number of computers in a classroom, computer network, Internet (access and speed) (Osika et al., 2009). After solving the problem of infrastructure, there are other negative factors that influence e-learning application. Thus, perceived adequacy of support (e.g. technical, pedagogical, personnel), as facilitating circumstance, has an important impact on applying e-learning in education (Timothy, 2009). Availability of information about the manner of applying e-learning technology in education process can positively influence teacher's adoption of e-learning (Kundi et al., 2010).

Since introduction of e-learning technology into academic institutions causes changes in structure, policies and organizational culture, it also brings about changes in organizational learning. Keller (2009) proved that organizational culture has the strongest impact on elearning technology integration by academic teachers through the level of organizational learning, thus the expected effort and observability have stronger connection with the lower level of organizational learning, while social influence and facilitating circumstances relate to the higher level of organizational learning. The author suggests that the teacher's attitude towards education quality needs to be examined. Numerous authors confirmed that institutional strategy is an important obstacle in adopting e-learning (Keller, 2009; Marwan \& Sweeney, 2010; Samarawickrema \& Stacey, 2007). Teacher's academic freedom and 
organizational culture of teaching also represent obstacles in in e-learning acceptance (Keller, 2009).

After accepting e-learning technology, teachers still point out the following obstacles in its use: work overload, question of property, required resources, professional growth and management (Marwan \& Sweeney, 2010). The academic institution's management has a great role in introducing and developing e-learning. Gautreau (2011) confirms the importance of adequate support and training factors, but also proves that reward and encouragement system and recognition of accomplishments are very important motivational factors in teachers adopting and developing e-learning.

However, even after removing many of the aforementioned obstacles, numerous study results indicate that time is the crucial factor that needs to be invested when changing to blended learning model, and it is connected to acquiring new knowledge, adjusting and implementing the course material to e-learning system, as well as to the lack of time for the requirements of the scientific research (Samarawickrema \& Stacey ,2007).

\section{Conclusion}

Numerous authors have tried to understand the problem of academic teachers accepting elearning technology by discovering and confirming the influence of many factors studied from different aspects, while using existing theories and models of innovation acceptance (as well as their combination) as basis for empirical research. Study results frequently confirm the factors: usefulness and ease of use of the e-learning technology. Authors have in different ways adapted the constructs from the existing theories and models, in which greater significance was given to the technical aspect of the e-learning technology, and not so much to the pedagogical aspect, which will only later gain more significance. Also, researches include more institutional factors and less situational ones (such as field of study characteristics and student characteristics) which represent important extrinsic motivational factors influencing the teachers when creating virtual learning environments. The researches are increasingly focused on the personality of teachers, as an intrinsic motivational factor, after certain institutional obstacles have been removed with the aim of creating encouragement measures for developing and applying e-learning. The training has been singled out as a separate category regarding that, apart from the required ICT infrastructure, acquiring new knowledge and skills is one of the essential factors in adopting e-learning. Learning through experience influences the creation of new values which become attitudes that have a strong impact on teacher's behavior towards e-learning technology. Therefore, the attitude and values are singled out as a separate category as well, linking together certain factors that influence them.

Because of the manner of academic teaching process, the most commonly used is blended learning model where teacher chooses the e-learning technology based on certain elements stated in this paper. The practice has shown that creating a blended learning environment is not easy and that teachers have problems in many stages of designing the virtual learning environment, from the analysis of the course requirements, analysis of the student requirements, application of instructional design model, e-learning technology use, not understanding the concept of the quality of e-learning process and many other factors. Based on existing study results in the field of academic teacher's accepting e-learning technology, the figure 4 shows intrinsic and extrinsic motivational factors which can serve as a foundation for theoretical models in the future empirical researches. 


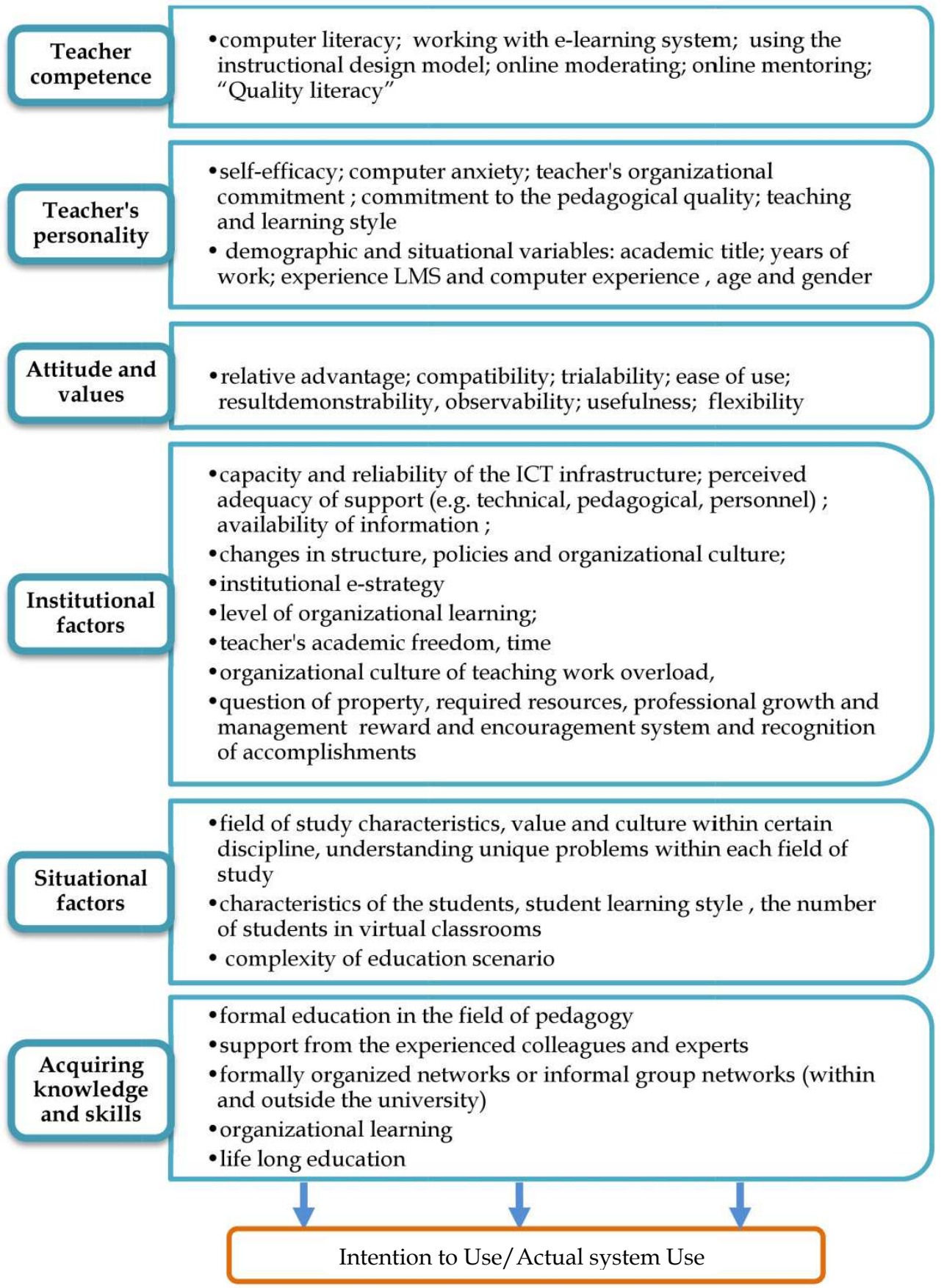

Fig. 4. Factors that influence academic teacher's acceptance of e-learning technology. 


\section{References}

Agarwal, R. (2000). Individual Acceptance of Information Technologies, in R. W. Zmud (Ed.), Framing The Domains of IT Management: Projecting the Future Through the Past, Cincinnati, OH: Pinnaflex Press, 85-104.

Ajzen, I.(1991). The Theory of Planned Behaviour, Organizational Behavior and Human Decision Processes, 50(2), 179-211.

Baia, P. (2009). The Role of Commitment to Pedagogical Quality: The Adoption of Instructional Technology in Higher Education, Study by Albany College of Pharmacy and Health Studies, ERIC: ED504055

Benchmarking of Virtual Campuses BENVIC, URL: http://www.benvic.odl.org/indexpr.html [14/7/2011]

Colorado, J. \& Eberle J. (2009). The Relationship of Student Demographics and Academic Performance in an Online Learning Environment. In T. Bastiaens et al. (Eds.), Proceedings of World Conference on E-Learning in Corporate, Government, Healthcare, and Higher Education 2009 (pp. 2469-2474). Chesapeake, VA: AACE

Davis, F. D. (1989). Perceived Usefulness, Perceived Ease of Use, and User Acceptance of Information Technology, MIS Quarterly, 13(3), 319-340.

Donnelly, R . \& Fitzmaurice M. (2005). Designing Modules for Learning. In G. O’Neill, S. Moore \& B. McMullin (Eds.) Emerging Issues in the Practice of University Learning and Teaching (pp. 99-110). Dublin: AISHE/HEA

Dugas, C. A. (2006). Adopter Characteristics and Teaching Styles of faculty Adopters and Nonadopters of a Course management System. Disseration. Indiana State University. Loetud

Ehlers, U. D. (2007). Quality Literacy - Competencies for Quality Development in Education and e-Learning, Technology \& Society , 10 (2), 96-108.

Fishbein, M. \& Ajzen I. (1975). Belief, attitude, intention and behavior: an introduction to theory and research, Addison-Wesley, Reading MA: Addison-Wesley

Gautreau, C. (2011). Motivational Factors Affecting the Integration of a Learning Management System by Faculty, California State University Fullerton, The Journal of Educators Online, Volume 8, Number 1, January 2011

Gibson, S.; Harris, M. \& Colaric, S. (2008). Technology acceptance in an academic context: faculty acceptance of online education. Journal of Education for Business, 83(6), 355359.

Grasha, A. F. (1994). A matter of style: The teacher as expert, formal authority, personal model, facilitator, and delegator. College Teaching. 42, 142-149.

ISO/IEC 19796-1:2005, Information Technology - Learning, Education, and Training Quality Management, Assurance and Metrics - Part 1: General Approach

ISO/IEC 19796-3:2009, Information technology - Learning, Education and Training Quality management, assurance and metrics-Part 3: Reference methods and metrics

Kanuka, H. (2006). Instructional design and e-learning: A discussion of pedagogical content knowledge as amissing construct, The e-Journal of Instructional Science and Technology, 9(2).

Keller, C. ; Lindh, J. ; Hrastinski, S. ; Casanovas, I. \& Fernandez, G. (2009). The impact of national culture on e-learning implementation: A comparative study of an Argentinean and a Swedish University. Educational Media International, 46(1), 67-80. 
Keller, C. (2009). User Acceptance of Virtual Learning Environments: A Case Study from Three Northern European Universities. Communications of the Association for Information Systems: Vol. 25, Article 38.

Kermek D.; Orehovački T. \& Bubaš G. (2007) Procjena i unapređenje kvalitete u eobrazovanju, Stručno-znanstveni skup "E-obrazovanje", Zbornik radova / Bubaš, Goran ; Kermek, Dragutin (ed). - Varaždin : Fakultet organizacije i informatike, 169-177

Kumarawadu, P. (2011). Motivation of online learners: Review of practies and emering trend, Sri Lanka Institute of Information Technology, URL:

http://www2.uca.es/orgobierno/ordenacion/formacion/docs/jifpev5-doc5.pdf $[14 / 7 / 2011]$

Kundi, G. ; Nawaz, A. \& Khan, S. (2010) The predictors of success for e-learning in higher education institutions (HEIs) In N-W.F.P, Pakistan, JISTEM Journal Of Information Systems And Technology Management, 7( 3), 545-578.

Liu, C. C. (2005). The Attitudes od University Teachers to adopt Information Technology in Teaching, Information Technoloogy Journal, 4 (4), 445-450.

Lofstrom, E. \& Nevgi, A. (2008). University teaching staffs' pedagogical awareness displayed through ICT - facilitated teaching, Interactive Learning Environments, vol. 16, p.2, pp. 101-116(16).

Lucas, S. \& Wright, V. (2009). Who Am I? The influence of teacher beliefs on instructional technology incorporation. The Journal on Excellence in College Teaching, 20(3), 77- 95.

Mahdizadeh, H. ; Biemans, H. \& Mulder, M. (2008). Determining Factors of the Use of ELearning Environments by University Teachers, Computers \& Education, 51, 142-154.

Malik, M.E.; Nawab, S. ; Naeem, B. \& Danish, R.Q. (2010). Job Satisfaction and Organizational Commitment of University teachers in Public Sector of Pakistan, International Journal of Business and Management, 5(4).

Marshall, S. \& Mitchell, G. (2004). Applying SPICE to e-learning: An e-learning maturity model?, Sixth Australasian Computing Education Conference (ACE 2004), Dunedin. U: R. Lister i A. Young (ur.) Conferences in Research and Practice in Information Technology, vol. 30., 185-191.

Marwan, A. \& Sweeney, T. (2010). Teachers' perceptions of educational technology integration in an Indonesian polytechnic, Asia Pacific Journal of Education, Volume 30, Number 4, 463-476(14).

Melis, E. ; Weber, M. \& Andrès, E. (2003). Lessons for (Pedagogic) Usability of eLearning Systems. World Conference on E-Learning in Corporate, Government, Healthcare, $\mathcal{E}$ Higher education. (1), 281-284.

Mihhailova, G. (2006). E-learning as internationalisation strategy in higher education: Lecturer's and student's perspective. Baltic Journal of Management, 1 (3), 270-284.

Moore, G. \& Benbasat, I. (1991). Development of an Instrument to Measure the Perceptions of Adopting an Information Technology Innovation. Information Systems Research, (2:3) 192-222.

Moscinska, K. \& Rutkowski, J. (2011).Barriers to introduction of e-learning: A case study In: Global Engineering Education Conference (EDUCON), 2011 IEEE, Amman, 4-6 April, $460-465$.

Nanayakkara, C. \& Whiddett, D. (2005). A model of user acceptance of e-learning technologies: A case study of a Polytechnic in New Zealand, 4th International 
Conference on Information Systems Technology and its Application (ISTA'2005), Palmerston North, New Zealand, GI.

Osika, E. R. ; Johnson, R.Y. \& Buteau, R. (2009).Factors influencing faculty use of technology in online instruction: A case study. Online Journal of Distance Learning Administration. 12(1)0

Ozkan, S. \& Findık, D. (2010). Work in Progress - Learning Management Systems Acceptances of Instructors from Various Departments: Empirical Investigation. Middle East, 26-28.

Pawlowski, J. M. (2006): ISO/IEC 19796-1: How to Use the New Quality Framework for Learning, Education, and Training. White Paper, Essen, Germany, 2006.

Parrish, P. E. (2007). Learning with Object. In Shank P, Carliner S (Eds), The e-learning Handbook: Past Promise, Present Challenges (pp. 215-241), San Francisko, CA:Pfeiffer

Rebman, C.; Cegielski, C. \& Kitchens, F. (2004). Web-Based Instructional Course Development: Lessons Learned and a Proposed Model, Journal of Informatics Education Research, (6:2), Summer 2004.

Renzi, S. (2008). Differences in University Teaching after Learning Management System Adoption: An Explanatory Model Based on Ajzen's Theory of Planned Behavior. PhD Thesis, University of Western Australia

Rogers, E. M. (1995). Diffusion of Innovations, 4thed. New York, Free Press

Rothery, A.; Cilia, J.; Stenalt, M. H. \& Dupuis, M. (2008). E-Learning Snapshots 2008. EUNIS2008, Aarhus University, Denmark, 2008.

Salmon, G. (2000) E Moderating- The Key to Teaching and learning Online. London: Taylor \& Francis Books Ltd

Samarawickrema, G. \& Stacey, E. (2007). Adopting Web-Based Learning and Teaching: A case study in higher education, Distance Education, 313 - 333.

Schneckenberg, D. (2008). Educating Tomorrow's Knowledge Workers: The concept of eCompetence and its application in international higher education Amsterdam: Eburon Academic Publishers.

Schneckenberg, D. (2007). Competence Reconsidered - Conceptual Thoughts on eCompetence and Assessment Models for Academic Staff. In: U. Bernath $\mathcal{E} A$. Sangra (Eds.), ASF Series, Vol. 13, 17-34.

Sørebø, Ø. \& Sørebø, A. M. (2008). Understanding e-learning satisfaction in the context of university teachers. Proceedings of World Academy of Science, Engineering and Technology, Bangkok

The Joint Information Systems Committee (JISC), URL: http://www.jiscinfonet.ac.uk/InfoKits/effective-use-of-VLEs/intro-toVLEs/introtovle-intro/index_html [14/7/2011]

Timothy, T. (2009). Modelling technology acceptance in education: A study of pre-service teachers. Computers $\mathcal{E}$ Education, 52(2), 302-312.

Venkatesh, V. \& Davis, F. D. (2000).A theoretical extension oft he technology acceptance model: four longitudinal field studies. Management Science, 46(2): 186-204.

Venkatesh, V. ; Morris, M. G.; Davis, G. B. \& Davis, F. D. (2003). User Acceptance of Information Technology: Toward a Unified View, MIS Quarterly, 27(3), 425-47. 
Weinert, F. E. (2008).Concept of Competence: a conceptual definition. In: D. S. Rychen \& L. H. Salganik (Eds.). Defining and Selecting Key Competencies, p46. Seattle, WA: Hogrefe \&Huber). 2001. 


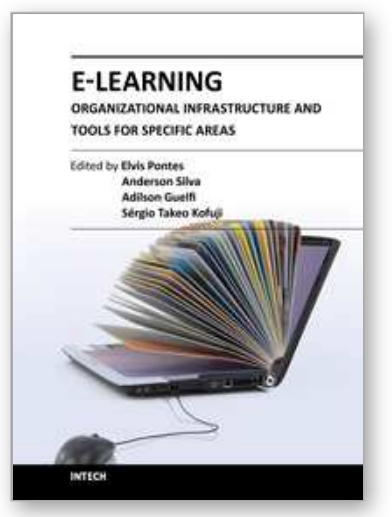

\author{
E-Learning-Organizational Infrastructure and Tools for Specific \\ Areas \\ Edited by Prof. Adilson Guelfi
}

ISBN 978-953-51-0053-9

Hard cover, 182 pages

Publisher InTech

Published online 17, February, 2012

Published in print edition February, 2012

Technology development, mainly for telecommunications and computer systems, was a key factor for the interactivity and, thus, for the expansion of e-learning. This book is divided into two parts, presenting some proposals to deal with e-learning challenges, opening up a way of learning about and discussing new methodologies to increase the interaction level of classes and implementing technical tools for helping students to make better use of e-learning resources. In the first part, the reader may find chapters mentioning the required infrastructure for e-learning models and processes, organizational practices, suggestions, implementation of methods for assessing results, and case studies focused on pedagogical aspects that can be applied generically in different environments. The second part is related to tools that can be adopted by users such as graphical tools for engineering, mobile phone networks, and techniques to build robots, among others. Moreover, part two includes some chapters dedicated specifically to e-learning areas like engineering and architecture.

\title{
How to reference
}

In order to correctly reference this scholarly work, feel free to copy and paste the following:

Snježana Babić (2012). Factors that Influence Academic Teacher's Acceptance of E-Learning Technology in Blended Learning Environment, E-Learning-Organizational Infrastructure and Tools for Specific Areas, Prof. Adilson Guelfi (Ed.), ISBN: 978-953-51-0053-9, InTech, Available from: http://www.intechopen.com/books/elearning-organizational-infrastructure-and-tools-for-specific-areas/factors-that-influence-academic-teacher-sacceptance-of-e-learning-technology-in-blended-learning-en

\section{INTECH}

open science | open minds

\section{InTech Europe}

University Campus STeP Ri

Slavka Krautzeka 83/A

51000 Rijeka, Croatia

Phone: +385 (51) 770447

Fax: +385 (51) 686166

www.intechopen.com

\section{InTech China}

Unit 405, Office Block, Hotel Equatorial Shanghai

No.65, Yan An Road (West), Shanghai, 200040, China 中国上海市延安西路65号上海国际贵都大饭店办公楼 405 单元

Phone: +86-21-62489820

Fax: $+86-21-62489821$ 
(C) 2012 The Author(s). Licensee IntechOpen. This is an open access article distributed under the terms of the Creative Commons Attribution 3.0 License, which permits unrestricted use, distribution, and reproduction in any medium, provided the original work is properly cited. 